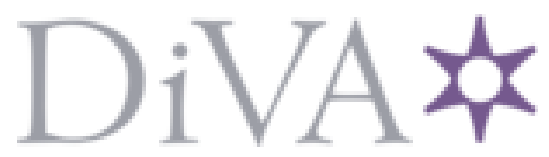

http://www.diva-portal.org

\title{
Postprint
}

This is the accepted version of a paper published in Clinical Biochemistry. This paper has been peerreviewed but does not include the final publisher proof-corrections or journal pagination.

Citation for the original published paper (version of record):

Helmersson-Karlqvist, J., Ärnlöv, J., Larsson, A. (2013)

Day-to-day variation of urinary NGAL and rational for creatinine correction.

Clinical Biochemistry, 46(1-2): 70-72

http://dx.doi.org/10.1016/j.clinbiochem.2012.09.022

Access to the published version may require subscription.

N.B. When citing this work, cite the original published paper.

Permanent link to this version:

http://urn.kb.se/resolve?urn=urn:nbn:se:uu:diva- 182320 


\section{Day-to-day variation of urinary NGAL and rational for creatinine correction}

Johanna Helmersson-Karlqvist ${ }^{\mathrm{a} *}$, Johan Ärnlöv ${ }^{\mathrm{b}, \mathrm{c}}$, Anders Larsson ${ }^{\mathrm{a}}$

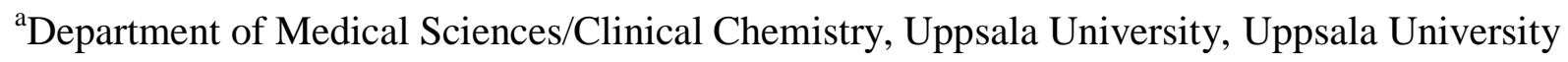
Hospital, SE-751 85 Uppsala, Sweden; anders.larsson@akademiska.se

${ }^{\mathrm{b}}$ Department of Public Health and Caring Sciences/Geriatrics, Uppsala University, Uppsala

Science Park, SE-751 85 Uppsala, Sweden; johan.arnlov@ pubcare.uu.se

${ }^{\mathrm{c}}$ School of Health and Social Studies, Dalarna University, Falun, Sweden

*Corresponding author: Johanna Helmersson-Karlqvist, Department of Medical

Sciences/Clinical Chemistry, Uppsala University Hospital, SE-75185 Uppsala, Sweden

Fax: +46-18-552562; Phone: +46-18-6114228

E-mail: Johanna.Helmersson_Karlqvist@ medsci.uu.se 


\section{Abstract}

Objectives: Clinical studies evaluating the new tubular biomarker urinary neutrophil gelatinase-associated lipocalin (U-NGAL) in urine increase and there is no consensus whether absolute U-NGAL concentrations or urinary NGAL/creatinine (U-NGAL/Cr) ratios should be used when chronic tubular dysfunction is studied. The aim was to study the biological variation of U-NGAL in healthy subjects and the rational for urinary Creatinine (U-Cr) correction in two different study samples.

Design and Methods: To study biological variation of U-NGAL and U-NGAL/Cr ratio and the association between U-NGAL and U-Cr in healthy subjects 13 young males and females (median age 29 years) collected morning urine in 10 consecutive days. Additionally, a random subsample of 400 males from a population-based cohort (aged 78 years) collecting 24-hour urine during one day was studied.

Results: The calculated biological variation for absolute U-NGAL was $27 \%$ and for UNGAL/Cr ratio $101 \%$. Absolute U-NGAL increased linearly with U-Cr concentration (the theoretical basis for creatinine adjustment $)$ in the older males $(\mathrm{R}=0.19, \mathrm{P}<0.001)$ and with borderline significance in the young adults $(\mathrm{R}=0.16, \mathrm{P}=0.08)$. The $\mathrm{U}-\mathrm{NGAL} / \mathrm{Cr}$ ratio was, however, negatively associated with creatinine in the older males $(\mathrm{R}=-0.14, \mathrm{P}<0.01)$ and in the young adults $(\mathrm{R}=-0.16, \mathrm{P}=0.07)$ indicating a slight "overadjustment".

Conclusions: The study provide some support for the use of U-NGAL/Cr ratio but the rather large biological variation and risk of possible overadjustment need to be considered. Both absolute U-NGAL and U-NGAL/Cr ratios should be reported for the estimation of chronic tubular dysfunction.

Keywords: biological variation, neutrophil gelatinase-associated lipocalin, tubular biomarker, creatinine ratio 
Abbreviations: CV, coefficient of variation; U-Cr, urinary Creatinine, U-NGAL, urinary neutrophil gelatinase-associated lipocalin

\section{Introduction}

Neutrophil gelatinase-associated lipocalin (NGAL) [1], also known as human neutrophil lipocalin (HNL) [2] and lipocalin-2, is a member of the lipocalin family of binding proteins and is in the circulation mainly produced by activated neutrophils. The main source of urinary NGAL (U-NGAL) is however tubular epithelial cells in the kidney [3]. NGAL is produced and secreted into the urine in response to ischemic kidney damage and is therefore a promising early indicator of tubulointerstitial damage $[4,5]$. Recent clinical studies show that U-NGAL reflect acute renal damage early [6-9] but may also signal chronic renal damage [10-13]. When mild to moderate increases in U-NGAL concentrations are expected it is of essence to know whether U-NGAL should be measured as absolute values or as a ratio to urinary Creatinine (U-Cr). There is no consensus how to best estimate U-NGAL in this sense. The aim of this study was to study the rational for U-Cr correction of U-NGAL using both young healthy subjects and a heterogeneous aged population and to study the biological dayto-day variation of U-NGAL in healthy subjects.

\section{Patients and methods}

To study the biological variation of U-NGAL and U-NGAL/Cr ratio and the associations between U-NGAL and U-Cr 13 young healthy male and female volunteers without medication (median age 29 years; interval 22-59 years) collected spot urine samples during ten successive days. The samples were collected in the morning (approximately 6-8 AM). 
Additionally, to study the associations between U-NGAL and U-Cr in an older age-group a random subsample of 400 males, out of 839 males, collecting 24-hour urine during one day in the forth examination cycle of Uppsala Longitudinal Study of Adult Men (aged 77-78 years) [14] were examined. The samples were stored frozen at $-70^{\circ} \mathrm{C}$ until analysis. The study has been cleared by the Ethics Review Board for human studies and patients have signed informed consent.

U-NGAL was analyzed with a commercial sandwich ELISA kit, (DY1757, R\&D Systems, Minneapolis, MN). The method has a total coefficient of variation (CV) of $2.4 \%$. U-Cr was analysed with IL Test creatinine 181672-00 on a Monarch 2000 analyser, Instrumental Laboratories, Lexington, MA. The total CV for the U-Cr assay was $2.4 \%$.

U-NGAL and U-NGAL/Cr ratio was skewed according to Shapiro-Wilks test $(\mathrm{W}<0.95)$ and was log-transformed. Both U-NGAL and U-NGAL/Cr ratio showed W >0.95 (Shapiro-Wilks test) after transformation, thus assumed to be normally distributed. We used linear regression and Pearson's correlation to study the linear associations between U-NGAL and U-NGAL/Cr ratio, respectively, and $\mathrm{U}-\mathrm{Cr}$ in both study samples. To describe the biological variation of absolute U-NGAL and U-NGAL/Cr ratio in the healthy young subjects total $\mathrm{CV}\left(\mathrm{CV}_{\text {tot }}\right)$ was calculated from the root mean square error using ANOVA. Analytical $\mathrm{CV}\left(\mathrm{CV}_{\text {ana }}\right)$ for the NGAL method was calculated using multiple measurements of the same sample at different concentrations. $\mathrm{CV}_{\text {ana }}$ for the U-NGAL/Cr ratio was estimated as the square root of the sum of the square of $\mathrm{CV}_{\text {ana }}$ for the NGAL method and the square of $\mathrm{CV}_{\text {ana }}$ for the $\mathrm{U}-\mathrm{Cr}$ method. $\mathrm{CV}$ due to biological variation $\left(\mathrm{CV}_{\text {biol }}\right)$ was estimated by the formula $\mathrm{CV}_{\text {tot }}{ }^{2}=\mathrm{CV}_{\text {biol }}{ }^{2}+\mathrm{CV}_{\text {ana }}{ }^{2}$. Calculations were performed with Stata 11.0 (College Station, TX). 


\section{Results}

Median and interquartile interval of U-NGAL and U-NGAL/Cr ratio in morning urine during 10 successive days in the healthy young subjects are presented in Table $1 . \mathrm{CV}_{\text {tot }}$ for U-NGAL was $27 \%$ and $\mathrm{CV}_{\text {ana }} 2.4 \%$, leading to a calculated $\mathrm{CV}_{\text {biol }}$ of $27 \% . \mathrm{CV}_{\text {tot }}$ for $\mathrm{U}-\mathrm{NGAL} / \mathrm{Cr}$ ratio was $101 \%$ and $\mathrm{CV}_{\text {ana }} 3.4 \%$, leading to a calculated $\mathrm{CV}_{\text {biol }}$ of $101 \%$. Median and interquartile interval of U-NGAL and U-NGAL/Cr ratio in the population of aged males was 17.3 [10.030.8] $\mu \mathrm{g} / \mathrm{L}$ and 2.0 [1.2-3.4] $\mu \mathrm{g} / \mathrm{mmol}$ creatinine, respectively. As shown in Figure 1A and 2A, the concentrations of absolute U-NGAL increased with U-Cr concentration, as could be expected (the theoretical basis for creatinine adjustment). The Pearson correlation coefficient $\mathrm{R}$ between concentrations was 0.16 and borderline significant $(\mathrm{p}=0.08)$ for young healthy subjects and $0.19(\mathrm{p}<0.001)$ for the aged male population. However, expressing NGAL as a NGAL/Cr ratio caused a certain amount of 'over-adjustment' as could be seen as negative associations in Figure 1B and 2B. The correlation coefficient $\mathrm{R}$ was -0.16 and again borderline significant $(\mathrm{p}=0.07)$ for young healthy subjects, but -0.14 and significant $(\mathrm{p}<0.01)$ for the aged male population.

\section{Discussion}

The positive linear associations between U-NGAL and U-Cr seen in both young, healthy subjects and in the older male subsample somewhat support the theoretical basis for creatinine adjustment. However, this study points out some important issues to consider. Firstly, the calculated biological variation of U-NGAL/Cr ratio was $101 \%$ and thus considerably larger than the calculated biological variation of absolute U-NGAL which was only $27 \%$. The theoretical basis for $\mathrm{U}-\mathrm{Cr}$ adjustment is to compensate for variations in urine concentrations (assuming a steady U-Cr excretion rate), thus reducing the variation of the biomarker. This study indicate however the opposite; a higher biological day-to-day variation in U-NGAL/Cr 
ratio compared to absolute NGAL. The biological variation of the $\mathrm{U}-\mathrm{NGAL} / \mathrm{Cr}$ ratio is however at a similar level as in a recent study where the biological variation was estimated to $81 \%$ for the U-NGAL/Cr ratio [15]. In the same study the biological variation of absolute UNGAL was $84 \%$ which is a considerably larger variation than in this study.

Secondly, it is important to bear in mind that adjustment with urinary creatinine may actually cause "overadjustment", as seen in the negative correlations between the U-NGAL/Cr ratio and creatinine in this study. An overadjustment of creatinine may potentially impact associations and interpretation of results in clinical studies. Given the relatively week correlation between U-NGAL and U-Cr and the risk of overadjustment by creatinine as discussed above it is reasonable to suggest that laboratories should report both absolute UNGAL and U-NGAL/Cr ratios for the estimation of chronic tubular dysfunction.

The study included apparently healthy subjects and participants from a community cohort who possible are healthier than the general population and the results of the study are not necessarily applicable to patients with specific diagnosis. Excretion of creatinine may vary with changes in glomerular filtration rate, thus the results may not be extrapolated to patients with acute kidney diseases [16]. To further evaluate the clinical importance and prognostic utility of U-NGAL versus U-NGAL/Cr ratio large prospective cohort studies are needed. In conclusion, this study provide some support for the use of U-NGAL/Cr ratio but the rather large biological variation and the risk of overadjustment must be taken into account when planning and interpreting a clinical study intended to study chronic tubular dysfunction.

\section{Acknowledgements}


We are grateful to Charina Brännström for skilled technical assistance. This work was supported by Uppsala-Örebro Regional Research Council (RFR), The Swedish Research Council (2006-6555), Swedish Heart-Lung foundation, and Dalarna University.

\section{Conflict of interest}

None. 


\section{References}

[1] Kjeldsen L, Johnsen AH, Sengelov H, Borregaard N. Isolation and primary structure of NGAL, a novel protein associated with human neutrophil gelatinase. J Biol Chem 1993;268:10425-32.

[2] Xu SY, Carlson M, Engstrom A, Garcia R, Peterson CG, Venge P. Purification and characterization of a human neutrophil lipocalin (HNL) from the secondary granules of human neutrophils. Scand J Clin Lab Invest $1994 ; 54: 365-76$.

[3] Mårtensson J, Bell M, Oldner A, Xu S, Venge P, Martling CR. Neutrophil gelatinase-associated lipocalin in adult septic patients with and without acute kidney injury. Intensive Care Med 2010;36:1333-40.

[4] Mishra J, Ma Q, Prada A, Mitsnefes M, Zahedi K, Yang J, et al. Identification of neutrophil gelatinaseassociated lipocalin as a novel early urinary biomarker for ischemic renal injury. J Am Soc Nephrol 2003;14:2534-43.

[5] Ding H, He Y, Li K, Yang J, Li X, Lu R, et al. Urinary neutrophil gelatinase-associated lipocalin (NGAL) is an early biomarker for renal tubulointerstitial injury in IgA nephropathy. Clin Immunol 2007;123:227-34.

[6] Ronco C. N-GAL: Diagnosing AKI as soon as possible. Crit Care 2007;11:173.

[7] Bennett M, Dent CL, Ma Q, Dastrala S, Grenier F, Workman R, et al. Urine NGAL predicts severity of acute kidney injury after cardiac surgery: A prospective study. Clin J Am Soc Nephrol 2008;3:665-73.

[8] Haase-Fielitz A, Bellomo R, Devarajan P, Story D, Matalanis G, Dragun D, et al. Novel and conventional serum biomarkers predicting acute kidney injury in adult cardiac surgery--a prospective cohort study. Crit Care Med 2009;37:553-60.

[9] Urbschat A, Obermuller N, Haferkamp A. Biomarkers of kidney injury. Biomarkers 2011;16 Suppl 1:S22-30.

[10] Mitsnefes MM, Kathman TS, Mishra J, Kartal J, Khoury PR, Nickolas TL, et al. Serum neutrophil gelatinase-associated lipocalin as a marker of renal function in children with chronic kidney disease. Pediatr Nephrol 2007;22:101-8.

[11] Bolignano D, Lacquaniti A, Coppolino G, Campo S, Arena A, Buemi M. Neutrophil gelatinase-associated lipocalin reflects the severity of renal impairment in subjects affected by chronic kidney disease. Kidney Blood Press Res 2008;31:255-8.

[12] Bolignano D, Lacquaniti A, Coppolino G, Donato V, Campo S, Fazio MR, et al. Neutrophil gelatinaseassociated lipocalin (NGAL) and progression of chronic kidney disease. Clin J Am Soc Nephrol 2009;4:337-44. 
[13] Bolignano D, Lacquaniti A, Coppolino G, Donato V, Fazio MR, Nicocia G, et al. Neutrophil gelatinaseassociated lipocalin as an early biomarker of nephropathy in diabetic patients. Kidney Blood Press Res 2009;32:91-8.

[14] Helmersson J, Vessby B, Larsson A, Basu S. Association of type 2 diabetes with cyclooxygenase-mediated inflammation and oxidative stress in an elderly population. Circulation 2004;109:1729-34.

[15] Delanaye P, Rozet E, Krzesinski JM, Cavalier E. Urinary NGAL measurement: Biological variation and ratio to creatinine. Clin Chim Acta 2011;412:390.

[16] Waikar SS, Sabbisetti VS, Bonventre JV. Normalization of urinary biomarkers to creatinine during changes in glomerular filtration rate. Kidney Int 2010;78:486-94. 


\section{Figure captions}

Figure 1. Linear association between $\log$ U-NGAL and U-Cr in 13 healthy subjects during 10 successive days. (A) A borderline significant positive association between uncorrected U-

NGAL and $U-C r ; y=2.68+0.04 x, R=0.16, P=0.08$. (B) After adjustment for creatinine, $U$ NGAL/Cr ratios are somewhat negatively associated with $\mathrm{U}-\mathrm{Cr} ; \mathrm{y}=1.33-0.04 \mathrm{x}, \mathrm{R}=-0.16, \mathrm{P}$ $=0.07$.

Figure 2. Linear association between $\log \mathrm{U}-\mathrm{NGAL}$ and $\mathrm{U}-\mathrm{Cr}$ in 400 aged males during one single day. (A) A highly significant positive association between uncorrected U-NGAL and $\mathrm{U}-\mathrm{Cr} ; \mathrm{y}=9.13+0.07 \mathrm{x}, \mathrm{R}=0.19, \mathrm{P}<0.001$ was seen. $(\mathrm{B})$ The $\mathrm{U}-\mathrm{NGAL} / \mathrm{Cr}$ ratio was negatively associated with $\mathrm{U}-\mathrm{Cr} ; \mathrm{y}=8.00-0.05 \mathrm{x}, \mathrm{R}=-0.14, \mathrm{P}<0.01$, indicating a possible “overadjustment". 
Table 1. Median concentrations (interquartile interval) of absolute U-NGAL, U-Cr and U-NGAL/Cr ratio in ten successive days in the 13 healthy subjects.

\begin{tabular}{|c|c|c|c|c|c|c|}
\hline \multirow[t]{2}{*}{ Subject } & \multicolumn{2}{|c|}{$\begin{array}{l}\text { U-NGAL } \\
(\mu \mathrm{g} / \mathrm{L})\end{array}$} & \multicolumn{2}{|c|}{$\begin{array}{c}\mathrm{U}-\mathrm{Cr} \\
(\mathrm{mmol} / \mathrm{L})\end{array}$} & \multicolumn{2}{|c|}{$\begin{array}{c}\text { U-NGAL/Cr ratio } \\
\text { ( } \mu \mathrm{g} / \mathrm{mmol} \text { creatinine) }\end{array}$} \\
\hline & median & $\begin{array}{l}25-75 \\
\text { percentile }\end{array}$ & median & $\begin{array}{l}25-75 \\
\text { percentile }\end{array}$ & median & $\begin{array}{l}25-75 \\
\text { percentile }\end{array}$ \\
\hline 1 & 13 & $6.4-22$ & 9.3 & $7.6-12$ & 1.2 & $0.62-1.7$ \\
\hline 2 & 2.9 & $1.8-4.5$ & 12 & $10-20$ & 0.21 & $0.15-0.34$ \\
\hline 3 & 38 & $32-48$ & 12 & $8.8-14$ & 3.3 & $1.9-5.3$ \\
\hline 4 & 24 & $20-42$ & 6.2 & $5.6-7.0$ & 3.8 & $3.0-7.6$ \\
\hline 5 & 7.8 & 4.6-14 & 4.7 & $4.2-6.6$ & 1.3 & $0.69-1.9$ \\
\hline 6 & 460 & $200-810$ & 11 & $6.5-14$ & 43 & $17-53$ \\
\hline 7 & 51 & $38-88$ & 12 & $11-13$ & 4.3 & $3.1-5.2$ \\
\hline 8 & 29 & $20-50$ & 18 & $15-23$ & 1.6 & $1.2-2.5$ \\
\hline 9 & 35 & $18-56$ & 16 & $12-20$ & 2.2 & $1.2-2.9$ \\
\hline 10 & 5.6 & $3.9-7.4$ & 13 & $9.0-14$ & 0.46 & $0.37-0.57$ \\
\hline 11 & 33 & $21-51$ & 6.0 & $5.7-7.2$ & 3.9 & 3.6-6.9 \\
\hline 12 & 30 & $17-42$ & 13 & $9.7-14$ & 2.6 & $1.2-4.5$ \\
\hline 13 & 24 & $15-31$ & 8.8 & $6.9-11$ & 3.0 & $2.0-4.2$ \\
\hline All & 24 & $10-47$ & 11 & 7.4-14 & 2.6 & $1.1-4.3$ \\
\hline
\end{tabular}


Figure 1.

A)

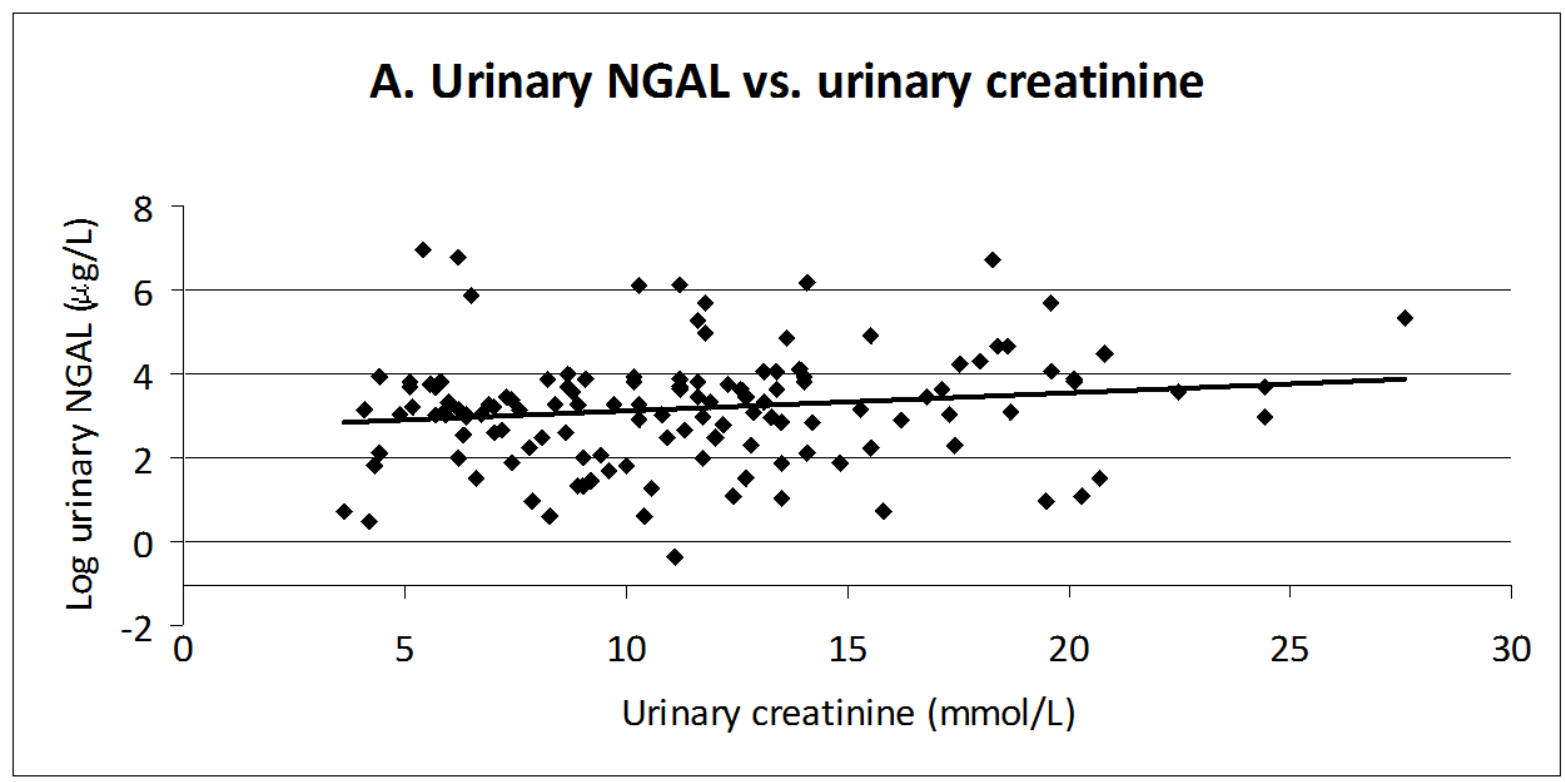

B)

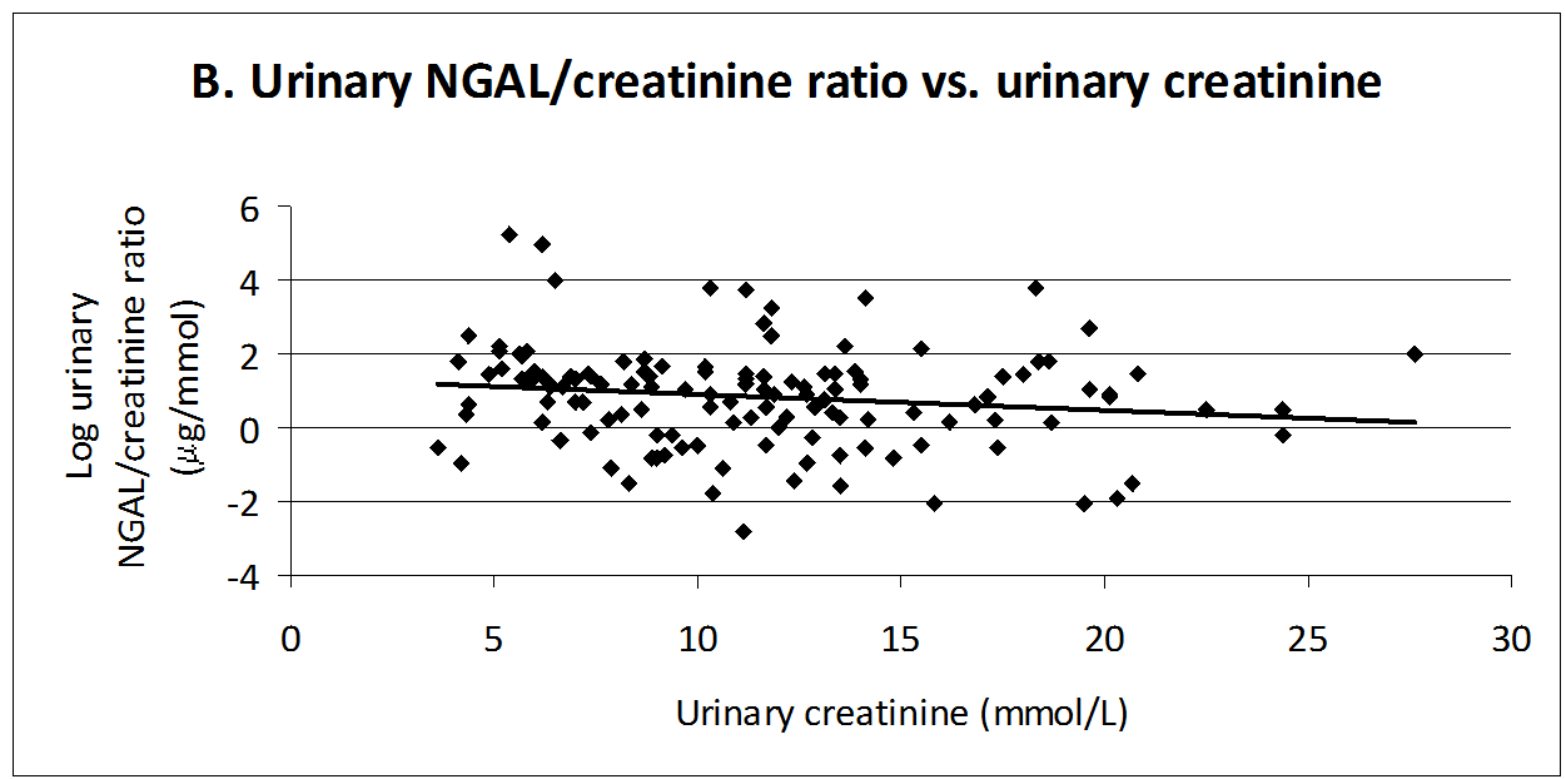


Figure 2.

A)

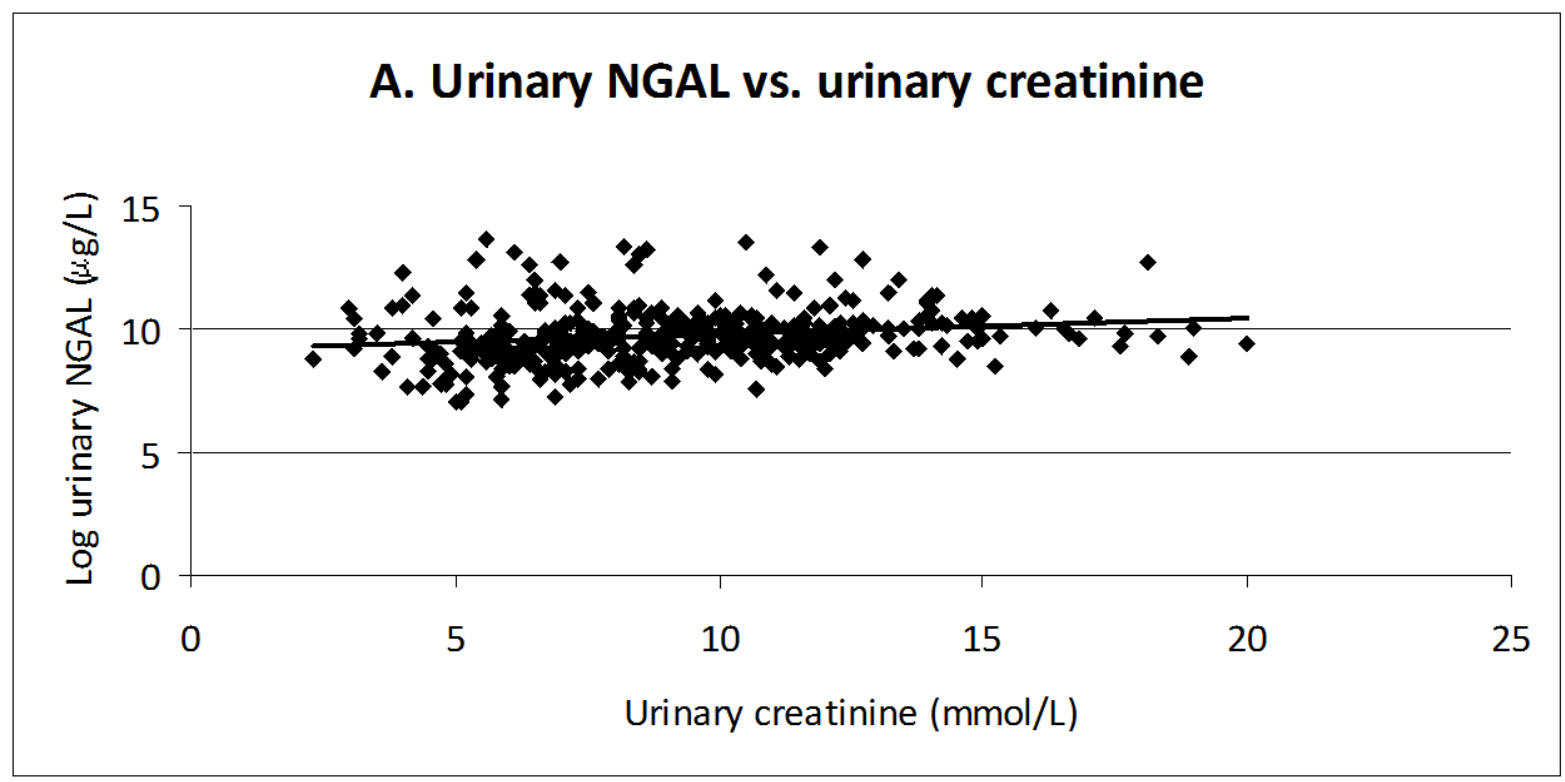

B)

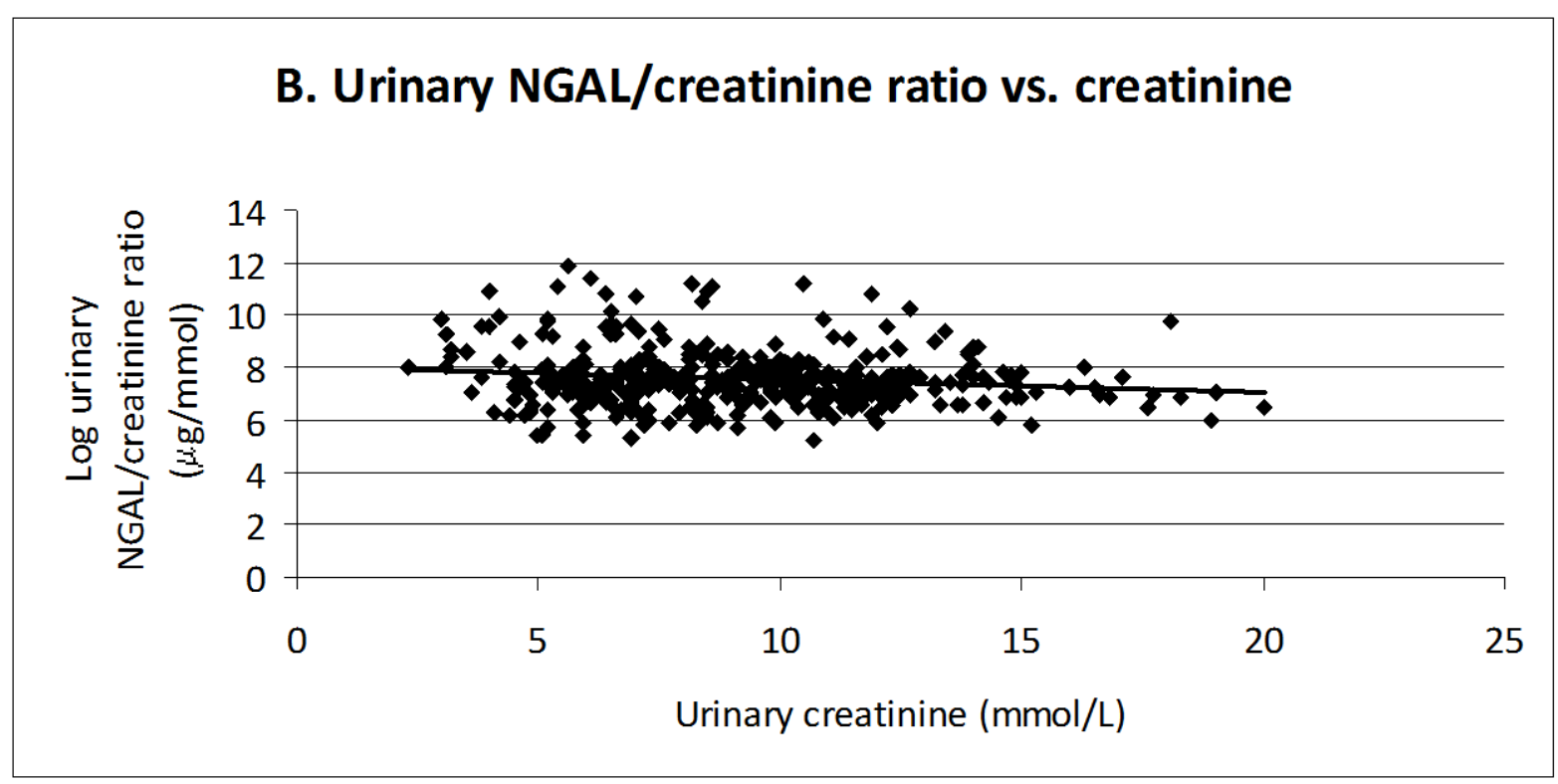

